University of Nebraska - Lincoln

DigitalCommons@University of Nebraska - Lincoln

Bureau of Sociological Research - Faculty

Publications

Bureau of Sociological Research (BOSR)

June 2008

\title{
The Importance of Motherhood among Women in the Contemporary United States
}

\author{
Julia McQuillan \\ University of Nebraska - Lincoln, jmcquillan2@Unl.edu \\ Arthur L. Greil \\ Alfred University \\ Karina M. Scheffler \\ Oklahoma State University \\ Veronica Tichenor \\ SUNY-Institute of Technology
}

Follow this and additional works at: https://digitalcommons.unl.edu/bosrfacpub

Part of the Sociology Commons

McQuillan, Julia; Greil, Arthur L.; Scheffler, Karina M.; and Tichenor, Veronica, "The Importance of Motherhood among Women in the Contemporary United States" (2008). Bureau of Sociological Research Faculty Publications. 7.

https://digitalcommons.unl.edu/bosrfacpub/7

This Article is brought to you for free and open access by the Bureau of Sociological Research (BOSR) at DigitalCommons@University of Nebraska - Lincoln. It has been accepted for inclusion in Bureau of Sociological Research - Faculty Publications by an authorized administrator of DigitalCommons@University of Nebraska - Lincoln. 
Published online June 5, 2008, in Gender \& Society (2008), doi 10.1177/0891243208319359. Copyright (C) 2008 Sociologists for Women in Society; published by Sage Publications. Used by permission. http://gas.sagepub.com/

The authors express their thanks to Ashley Frear Cooper, Denise Copelton, Sandy Bender Fromson, Mary Casey Jacob, Naomi Lacy, David R. Johnson, Laurie Scheuble, Katie Slausin, Katie Johnson, Lynn White, and Susan Wortmann for their assistance with this paper, and to Dana Britton for extensive editing help.

The data for this paper was supported by NICHD grant \#1R01HD044144 01A1.

An earlier version of this paper was presented at the American Sociological Association meeting in New York, NY, August, 2007.

\title{
The Importance of Motherhood among Women in the Contemporary United States
}

\author{
Julia McQuillan, University of Nebraska-Lincoln \\ Arthur L. Greil, Alfred University \\ Karina M. Shreffler, Oklahoma State University \\ Veronica Tichenor, SUNY-Institute of Technology
}

\begin{abstract}
We contribute to feminist and gender scholarship on cultural notions of motherhood by analyzing the importance of motherhood among mothers and non-mothers. Using a national probability sample $(N=2,519)$ of U.S. women ages $25-45$, we find a continuous distribution of scores measuring perceptions of the importance of motherhood among both groups. Employing OLS multiple regression, we examine why some women place more importance on motherhood, focusing on interests that could compete with valuing motherhood (e.g., education, work success, leisure), and controlling for characteristics associated with becoming a mother. Contrary to cultural schemas that view mother and worker identities as competing, we find that education level is not associated with the importance of motherhood for either group and that valuing work success is positively associated with valuing motherhood among mothers. Consistent with feminist explanations for delayed fertility, valuing leisure is negatively associated with valuing motherhood for non-mothers.
\end{abstract}

Keywords: motherhood, family, pronatalism, work-life, schemas, values, identity 


\section{Introduction}

Do women who value success in paid work consider motherhood less important? The dramatic entry of mothers into the paid labor force in the 1970s (Bianchi and Casper 2002) has raised questions about the importance of motherhood in women's lives. The reality of contemporary social structures in the United States-including workplace organizations, the structure of public education, and the gendered division of childcare and housework - make combining employment and motherhood challenging for most American women (see, for example, Crittenden 2001; Williams 2000). Gendered organizations that presume a flow of support from home (Britton 2000; Williams 2000) compete with the "motherhood mandate" that demands intensive mothering (Hays 1996). There is evidence that many American employers construct women as either mothers or workers, implicitly assuming that women cannot value both equally (Correll, Bennard, and Paik 2007; Kennelly 1999). We do not know, however, if American women share and embrace these historically-bound gendered constructions of what "mothers" and "workers" (Acker 2006) are supposed to be.

Motherhood is central to contemporary gendered expectations for women (Ridgeway and Correll 2004). The cultural expectation to bear and rear children is so strong that parenthood appears normative and childlessness deviant (Ulrich and Weatherall 2000). The "naturalness" of wanting and enjoying motherhood has been explored and challenged by several scholars who show the force of gendered expectations that conflate motherhood and femininity (Ireland 1993). The cultural tensions between valuing motherhood success and valuing work success have been characterized as "competing devotions" (Blair-Loy 2003), and largely anecdotal accounts of lower rates of motherhood among highly-successful career women (e.g., Hewlett 2002) add weight to the idea that women seeking careers must make choices between devotion to family and devotion to career. But does this mean that women who think motherhood is important do not value work success, and/or that women who value work success do not think that motherhood is important? Our goal in this article is to contribute to feminist and gender scholarship on motherhood by assessing whether there is in fact a difference in the importance of motherhood between mothers and non-mothers, and why this difference might exist. In particular, we assess the distribution of attitudes about the importance of motherhood among reproductive-age mothers and non-mothers, and explore the fruitfulness of various perspectives for explaining the distribution. Ultimately our findings 
challenge the thinking that motherhood inherently competes with work and reinforce efforts to restructure gendered organizations, institutions, policies, and families to facilitate better work-life integration.

\section{Theoretical Frameworks}

In the absence of theories specifically addressing the importance of motherhood in women's lives, we use theoretical perspectives from Bulcroft and Teachman's (2004) review of research on childlessness. They describe three kinds of explanations in childlessness research for voluntary childlessness: rational choice/economic, culture and identity, and lifecourse/situational theories. Each approach suggests specific concepts that should be associated with the importance of motherhood for women.

\section{Rational Choice/Economic Approaches}

A rational choice approach to the importance of motherhood focuses on the perceived rewards and costs of bearing children (Becker 1991; Friedman, Hechter, and Kanazawa 1994; Morgan and King 2001; Schoen et al. 1997). There is considerable evidence that combining employment and motherhood has many costs for women (Crittenden 2001; England 2005) but combining employment and fatherhood has benefits for men (Correll, Bennard, and Paik 2007; Glauber 2008). The costs of motherhood are particularly acute when work-family policies are limited, as they are in the United States (Misra, Moller, and Budig 2007). From a rational choice perspective, children provide potential rewards such as support in old age, affection, social approval, social capital, reduction of uncertainty, and marital stability. Children also present potential costs, particularly for women, including less time, money, emotional energy, likelihood of work advancement, or economic opportunities. These gendered benefits and costs mean that mothers grapple more with the meaning of their employment for child well-being and that all women are subject to public debate about the appropriateness of employment. Fathers rarely face similar tensions (Wall and Arnold 2007).

We include the rational choice perspective to understanding the importance of motherhood because it is common in research on fertility behavior (e.g., Hechter and Kanazawa 1997; Yang and Morgan 2003), where it is applied to understand and predict childbearing. It is important to recognize, however, that rational choice theories have been criticized by gender scholars for under-theorizing gender as a relevant social-structural constraint on 
behavior, and overemphasizing free choice (England and Kilbourne 1990; Risman and Ferree 1995). Demographers also recognize that economicallyfocused perspectives such as rational choice can downplay intangible rewards, such as emotional bonds and pleasure from children (Morgan and King 2001; Nock 1987) and hence underestimate the value of children relative to other costs and benefits.

Because more educated women have greater economic opportunities and more alternative sources of self esteem than less-educated women, the rational choice perspective suggests that level of education will be inversely related to the importance of motherhood. There is empirical evidence that the motherhood wage penalty increases with education level (Anderson, Binder, and Krause 2002), and that higher education is associated with lower valuing of children and higher odds of being voluntarily childfree (Houseknecht 1987; Myers 1997). Average fertility rates are higher for Black women than white women in the United States, but this is largely a function of educational attainment; higher education is associated with delayed and lower fertility for both Black and white American women (Yang and Morgan 2003).

The logic of rational choice also suggests that motherhood should exact greater costs from women who are employed and who are more committed to their jobs or careers. Much lower rates of motherhood among managers (Wood and Newton 2006), for example, suggest that women see motherhood as a likely barrier to career success. Blair-Loy (2003) and Stone (2007) report that most of the women whom they interviewed highly valued both motherhood and career success but could not negotiate workplace demands so as to enable them to carry out their goals. Presser (2005) argues that reliable contraception and greater availability of abortion have helped women delay marriage and childbearing, contributing to more experience of and appreciation for leisure time, and greater reluctance to invest in intensive mothering.

We developed the following hypotheses based on rational choice/economic perspectives:

1a: Higher valuing of work success should be associated with lower importance of motherhood;

1b: Higher valuing of leisure should be associated with lower importance of motherhood;

1c: Full-time employment should be associated with lower importance of motherhood than part-time employment, and women in both groups should place less importance on motherhood than women not in the paid labor force; and

1d: Women with higher levels of education should place lower importance on motherhood than those with lower levels. 


\section{Culture and Identity Approaches}

Culture and identity approaches to motherhood emphasize the motherhood mandate and pronatalist normative pressures on women in the United States. Religious and gender ideologies are both vital cultural factors that are likely to influence the importance of motherhood. Because many religions embrace pronatalist ideals, we expect motherhood to be more important to more religious women. There is evidence that higher religiosity is associated with less acceptance of childlessness (Houseknecht 1987; Koropeckyj-Cox and Pendell 2007a). We also expect that women who have more egalitarian gender expectations will place less importance on motherhood because more egalitarian women are more accepting of childlessness (Koropeckyj-Cox and Pendell 2007b).

Race and ethnicity have long been central to research on childlessness and intentions to remain childless (Yang and Morgan 2003). No single picture emerges from this research, however. There is evidence that white women are more likely to postpone childbearing and to express the intention to remain childless than Black women (Heaton, Jacobson and Holland 1999; Myers 1997), but this may be a function of education (Yang and Morgan 2003). Landry (2002) argues that the "cult of domesticity" never held the same sway for Black women as it did for white women, whom Collins (1990) suggests long ago rejected the notion of exclusive, intensive mothering. In research on women of Mexican origin, Segura (1994) finds complementary, rather than contradictory, attitudes toward work and motherhood. Still other work suggests, however, that low-income Black and Hispanic women may place a higher value on children (Dunlap, Sturzenhofecker, and Johnson 2006; Edin and Kefalas 2005; Kendall et al. 2005) than middle-class mothers of any racial group.

We combined insights from research and theorizing about cultural effects on the meanings of work and motherhood for women to construct the following hypotheses:

2a: Higher religiosity should be associated with higher importance of motherhood;

2b: More egalitarian gender attitudes should be associated with lower importance of motherhood;

If, as the literature suggests, white women are more affected by the cult of domesticity than women from other racial groups, then we should expect the following:

2c: White women will exhibit higher importance of motherhood than women from other racial groups.

If on the other hand higher fertility rates among Black and Hispanic women re- 
flect higher importance of motherhood (rather than blocked opportunities for meaningful work or leisure opportunities), then we expect that:

2d: Black and Hispanic women will place higher importance on motherhood than white women.

\section{Life-course/Situational Approaches}

A life-course approach to explaining variations in the importance of motherhood suggests that when life circumstances change, perceptions of motherhood change as well (Elder 1985). As age is an important marker of changes in life circumstances, it should be associated with valuing motherhood. Older women, who came of age in a different, more conservative, generation, have more negative attitudes toward childlessness (e.g., Heaton, Jacobson, and Holland 1999). We might expect that older women will place more importance on motherhood than younger women (KoropeckyjCox and Pendell 2007a). Crittenden (2001), however, provides evidence that more life experience should lower the importance of motherhood for older women, who have encountered the difficulties of combining work and motherhood.

It is likely that the importance of motherhood varies with marital status. Because children are normatively associated with heterosexual marriage, married women should attribute more importance to motherhood than single or cohabiting women (Schoen et al. 1997). This picture is complicated by insights from Edin and Kefalas (2005), who find that the association between marriage and childbearing is weaker for low income women. Lesbians do not share the same opportunities for marriage as heterosexual women, and some evidence suggests there are lower normative expectations for motherhood among lesbians (Gillespie 2003). Motherhood, however, is central to the lives of many lesbians (Lewin 1993).

Perhaps the most important factor influencing women's attitudes about the importance of motherhood should be motherhood itself. Women without children are likely to value motherhood less, and may focus instead on work or on leisure. Conversely, women without children could have idealized images of what motherhood will be like and thus place a higher value on the importance of motherhood. The realities of motherhood in the context of greedy workplaces and expectations of intensive mothering could combine to temper women's expectations about the possibilities of combining work, family, and leisure.

We constructed the following hypotheses based on life-course/situational perspectives: 
3a: Older women should place higher importance on motherhood;

3b: Marriage should be associated with higher importance of motherhood values compared to other relationship statuses;

3c: Mothers should have higher importance of motherhood values than non-mothers.

\section{Methodology}

\section{The Sample}

Our data come from an ongoing, national random-digit-dialing telephone survey designed to study infertility. We have 2,576 completed interviews with women age 25 to 45 in the United States (and a fraction of their partners), collected between September 2004 and December 2005. We draw on the responses for the 98 percent $(N=2,519)$ with complete data for the variables in these analyses. The resulting sample includes 2,023 mothers and 496 non-mothers. We reserved the partner data for a future study. Sampling procedures and selection criteria were used to ensure that the sample would adequately represent women from racial/ethnic minority groups, women who have experienced infertility, and women who are at higher risk for experiencing infertility. Because of the selection criteria, the sample disproportionately represents women with current or potential infertility and women from underrepresented racial/ethnic minority groups relative to their representation in the national population. Therefore, we used a weight variable that adjusts the sample to be representative of women in the United States between the ages of 25 to 45 . The study is designed to assess social and health factors related to reproductive choices and fertility for U.S. women. A "planned missing" design was used to provide a way to incorporate measures of all of the necessary theoretical concepts while minimizing respondent burden. The completion rate for this sample is 53 percent.

\section{Concepts and Measures}

Importance of Motherhood. The dependent variable, importance of motherhood, was constructed by averaging responses to five questions. Four items are measured on Likert scales (strongly agree to strongly disagree): 1) "Having children is important to my feeling complete as a woman," 2) "I always thought I would be a parent," 3) "I think my life will be or is more fulfilling with children," and 4) "It is important for me to have children." A fifth item was measured on a scale from very important to not im- 
portant: 5) "How important is each of the following in your life ... raising children?" Factor analyses showed that these items formed a single factor that explained 64 percent of the variance. The Cronbach's alpha is high $(\alpha$ $=.86$ ). This scale has a slight positive skew (1.79).

Rational Choice/Economic Measures. Two subjective measures of the costs of motherhood were included: an indicator for valuing work success ("How important is being successful in my line of work?" 1 = very important) and an indicator for valuing leisure ("How important is having leisure to enjoy my own interests?" 1 = very important), both compared to responses indicating less than very important $(=0)$. Because women with more years of education experience potentially higher opportunity costs in choosing motherhood, we include years of education as a rational choice measure. Employment was measured by two variables indicating full-time employment or part-time employment compared to no employment.

Culture and Identity Measures. Race/Ethnicity was measured by three indicator variables (Black, Hispanic or "other" compared to non-Hispanic white). Religiosity was measured by four questions: 1) "How often do you attend religious services?" 2) "About how often do you pray?" 3) "How close do you feel to God most of the time?" and 4) "In general, how much would you say your religious beliefs influence your daily life?" Because these four items were measured on different scales, they were combined by first standardizing and then taking the mean. These items form a single factor and have a high reliability $(\alpha=.78)$. Gender egalitarian attitudes were measured by a single dichotomous variable that indicates a gender egalitarian response to either of the following statements: "It is much better for everyone if the man earns the main living and the woman takes care of the home and family," and "If a husband and a wife both work full-time they should share household tasks equally."

Life-course and Situational Measures. We use a broad conceptualization of "mother," and therefore put women who have not given birth, have not adopted children, and have not been formal or informal foster parents in the "non-mother" $(=1)$ category and contrasted this group with women who fit any category of mother $(=0)$. Because of sample-size limitations, for this study, we do not separate the many combinations of ways of being a mother (e.g., only biological children, biological and step, foster only, adopted only, etc). Age was measured in years. Both a linear and a squared term were included to assess possible nonlinearity. Relationship status was measured by five indicator variables (cohabiting, divorced, widowed, separated, never married) compared to those who are married. 
Control Variables. General health was measured by a single item: "Now I have some questions about your health. In general, would you say your own health is excellent, good, fair, or poor?" This variable was recoded so that high values indicate excellent health. Because some women are prevented from having children because of chronic health conditions, we included an indicator variable based upon the following question: "Do you have any chronic health problems?" Self identifying as a person with an infertility problem was measured by an affirmative answer to the question: "Do you think of yourself as someone who might have trouble getting pregnant?" and compared to those who answered no. Responses to three questions were combined to measure economic hardship: 1) "During the last 12 months, how often did it happen that you had trouble paying the bills?"

2) "During the last 12 months, how often did it happen that you did not have enough money to buy food, clothes, or other things your household needed?" and 3) "During the last 12 months, how often did it happen that you did not have enough money to pay for medical care?" This is a unidimensional scale with high reliability $(\alpha=.82)$.

Our goal is to explore the fruitfulness of rational choice/economic, culture/identity, and life-course/situational explanations for variations in the importance of motherhood. In addition to expecting importance of motherhood to differ on average between mothers and non-mothers, we also anticipate that expected associations (slopes) will depend upon motherhood status. Therefore, we run separate multiple regression models and compare slopes for mothers and non-mothers, controlling for other characteristics in the model. Finally, we control for perception of a fertility problem, general health, the presence of a chronic health problem, and economic hardship to account for barriers to fertility.

\section{RESULTS}

Table 1 provides sample characteristics by motherhood status and tests for differences between mothers and non-mothers using t-tests for means or proportions as appropriate. These descriptive statistics indicate that average importance of motherhood is significantly higher for mothers than non-mothers. The large difference in standard deviations also indicates that there is less variance in scores among mothers than non-mothers-in simple terms, that there is more consistency in attitudes about mothering among those who are mothers.

Figure 1 illustrates this pattern in more detail, by presenting the scores clustered into four categories for mothers and non-mothers. Importance of 
TABLE 1: Descriptive Statistics for the Variables Included in the Analyses

\begin{tabular}{|c|c|c|c|c|c|c|}
\hline & \multicolumn{2}{|c|}{$\begin{array}{c}\text { Mother } \\
n=2,023 \\
\text { Mean or }\end{array}$} & \multicolumn{2}{|c|}{$\begin{array}{c}\text { Non-mother } \\
n=496\end{array}$} & \multirow{2}{*}{\multicolumn{2}{|c|}{ Alpha }} \\
\hline & $\begin{array}{l}\text { Mean or } \\
\text { Proportion }\end{array}$ & SD & $\begin{array}{l}\text { Mean or } \\
\text { Proportion }\end{array}$ & SD & & \\
\hline Importance of Motherhood & 3.48 & .49 & 2.73 & .87 & .86 & $* * *$ \\
\hline \multicolumn{7}{|l|}{$\begin{array}{l}\text { Rational Choice (social exchange/ } \\
\text { economic resources) }\end{array}$} \\
\hline Work Important & .50 & - & .56 & - & - & $*$ \\
\hline Leisure Important & .41 & - & .62 & - & - & $* * *$ \\
\hline Works Full-Time & .52 & - & .76 & - & - & $* * *$ \\
\hline Works Part-Time & .14 & - & .08 & - & - & $* * *$ \\
\hline Education (years) & 14.30 & 2.72 & 15.98 & 2.50 & - & $* * *$ \\
\hline \multicolumn{7}{|l|}{ Culture and Identity } \\
\hline Hispanic & .16 & - & .09 & - & - & $* * *$ \\
\hline Black & .21 & - & .13 & - & - & $* * *$ \\
\hline Other Race/Ethnicity & .02 & - & .06 & - & - & $* * *$ \\
\hline Religiosity & .09 & .79 & -.36 & .98 & .78 & $* * *$ \\
\hline Egalitarian Attitudes & .53 & - & .72 & - & - & $* * *$ \\
\hline \multicolumn{7}{|l|}{ Life Course/Situational } \\
\hline Age & 35.52 & 5.82 & 33.10 & 6.38 & - & $* * *$ \\
\hline Cohabiting & .01 & - & .02 & - & - & \\
\hline Divorced & .09 & - & .06 & - & - & $*$ \\
\hline Widowed & .01 & - & .00 & - & - & - \\
\hline Separated & .04 & - & .01 & - & - & $* * *$ \\
\hline Never Married & .15 & - & .51 & - & - & $* * *$ \\
\hline \multicolumn{7}{|l|}{ Control Variables } \\
\hline Economic Hardship & 1.64 & .80 & 1.37 & .67 & .82 & $* * *$ \\
\hline General Health & 3.11 & .75 & 3.22 & .70 & - & $* *$ \\
\hline Chronic Health Problem & .25 & - & .23 & - & - & - \\
\hline Self Identifies Fertility Problem & .25 & - & .25 & - & - & - \\
\hline
\end{tabular}

${ }^{*} p<.05,{ }^{* *} p<.01,{ }^{* * *} p<.001$

NOTE: Significance is for the $t$-test for the differences in means or proportions as appropriate; $N=2,519-N a t i o n a l$ random sample of women aged 25-45; weighted.

motherhood scores cluster at higher values for mothers and non-mothers, but the responses are more spread out for non-mothers. Although there are very few low scores for mothers, there are cases at each value (1 through 4$)$ in both groups. The figure shows that some non-mothers consider motherhood very important, while few mothers' scores indicate low importance of motherhood.

From these data we cannot tell what this similarity reflects. Selection, social desirability, and cognitive dissonance could all confound the association between motherhood status and self reports of the importance of motherhood. First, it is likely that women who highly value motherhood 


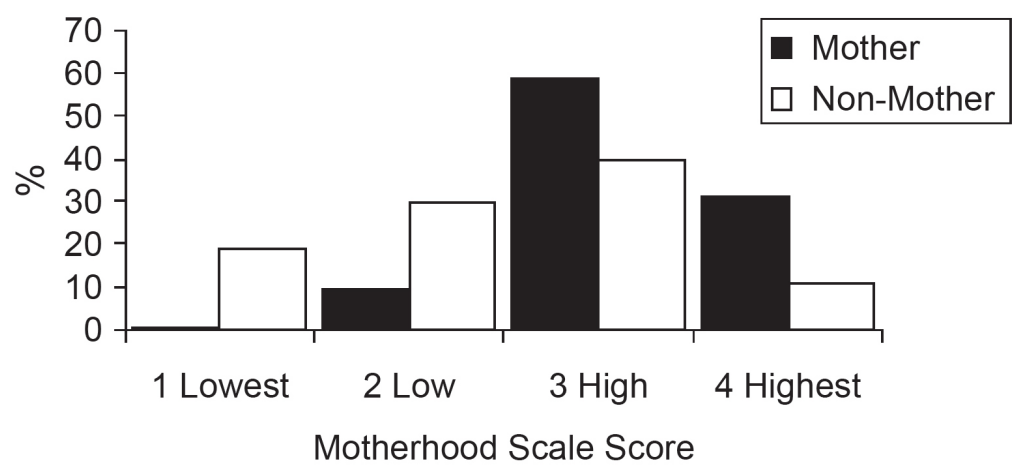

Figure 1: Percent of Women by Motherhood Importance Scores and Motherhood Status

will more quickly select into motherhood if they can. Cross-sectional data cannot definitively determine if an association between motherhood status and importance of motherhood indicates selection or causation. Second, it is likely that social desirability effects also contribute to mothers providing responses that indicate higher valuing of motherhood, regardless of their "true" attitudes. Third, cognitive dissonance could contribute to mothers believing that motherhood is important because otherwise it would be difficult to reconcile their status with their beliefs (Festinger, Riecken, and Schachter 1956).

However, there is some evidence that women who value motherhood more are more likely to become mothers. Average differences between mothers and non-mothers are significant for most of the variables in the expected directions (e.g., a smaller proportion of mothers report that work or leisure is very important or that they work full time, mothers have less egalitarian attitudes than non-mothers, and a higher proportion of mothers identify as Hispanic or Black). Also consistent with other studies and pronatalism in many religions, religiosity scores are significantly higher among mothers than among non-mothers. The majority of the sample is married, but non-mothers are much less likely to be married.

The multiple regression analysis results are reported in Table 2. Contrary to the rational choice prediction in Hypothesis 1a, there is a significant positive association between valuing work success and importance of motherhood for mothers. The association for non-mothers is not significantly different from zero, nor is the difference in slopes between mothers and non-mothers significant. These results are consistent with the find- 
TABLE 2: Importance of Motherhood Regressed on Rational Choice, Culture, Identity, Life Course, Situational Variables by Parenthood Status

\begin{tabular}{|c|c|c|c|c|c|c|c|c|c|c|}
\hline \multirow[b]{3}{*}{ Work Important } & \multicolumn{3}{|c|}{$\begin{array}{l}\text { Mothers } \\
(n=2,023)\end{array}$} & & \multicolumn{3}{|c|}{$\begin{array}{l}\text { Non-Mothers } \\
(n=496)\end{array}$} & \multirow{2}{*}{\multicolumn{3}{|c|}{$\begin{array}{l}\text { Absolute } \\
\text { Difference } \\
\text { (Mother - } \\
\text { Non-mother) }\end{array}$}} \\
\hline & $B$ & $S E$ & Beta & & $B$ & $S E$ & Beta & & & \\
\hline & .052 & .020 & .053 & $* *$ & -.013 & .063 & -.008 & - & .065 & - \\
\hline Leisure Important & -.003 & .020 & -.003 & - & -.204 & .065 & -.114 & ** & .200 & $* * *$ \\
\hline Works Full-Time & -.098 & .022 & -.099 & $* * *$ & .075 & .085 & .037 & - & .174 & * \\
\hline Works Part-Time & -.006 & .030 & -.004 & - & -.010 & .128 & -.003 & - & .004 & - \\
\hline Education (years) & .005 & .004 & .025 & - & .019 & .013 & .056 & - & .015 & - \\
\hline Hispanic & -.123 & .028 & -.092 & $* * *$ & -.130 & .105 & -.043 & - & .007 & - \\
\hline Black & -.161 & .027 & -.133 & *** & -.008 & .096 & -.003 & - & .153 & * \\
\hline Other Race/Ethnicity & -.006 & .066 & -.002 & - & .242 & .122 & .069 & * & .249 & * \\
\hline Religiosity & .065 & .013 & .104 & $* * *$ & .077 & .033 & .087 & * & .012 & - \\
\hline Egalitarian Attitudes & -.122 & .020 & -.123 & $* * *$ & -.377 & .070 & -.195 & $* * *$ & .256 & $* *$ \\
\hline Age & -.003 & .002 & -.032 & - & -.069 & .005 & -.509 & $* * *$ & .067 & - \\
\hline Age Squared & .000 & .000 & -.012 & - & .000 & .001 & .019 & - & .001 & - \\
\hline Cohabiting & -.120 & .087 & -.027 & - & .088 & .209 & .014 & - & .208 & - \\
\hline Divorced & .001 & .033 & .000 & - & -.027 & .129 & -.007 & - & .027 & - \\
\hline Widowed & -.274 & .092 & -.057 & $* *$ & .174 & .424 & .014 & - & .448 & - \\
\hline Separated & -.078 & .049 & -.031 & - & -.107 & .370 & -.010 & - & .029 & - \\
\hline Never Married & -.168 & .030 & -.121 & $* * *$ & .004 & .067 & .002 & - & .172 & * \\
\hline Constant & 3.646 & .025 & - & $* * *$ & 2.917 & .118 & - & $* * *$ & .729 & $* * *$ \\
\hline Adjusted R-square & .100 & - & - & *** & .319 & - & - & - & .219 & $* * *$ \\
\hline
\end{tabular}

${ }^{*} p<.05 * * p<.01 * * * p<.001$

NOTE: $N=2,519-N a t i o n a l$ random sample of women aged 25-45; weighted. All continuous variables are mean centered. The significance of the difference between mother and nonmother coefficients were tested using interaction terms in a combined model. This model controls for economic hardship, self-rated health, a chronic health condition, and self identifying as having a fertility problem.

ings of many qualitative studies that find many mothers value motherhood and employment simultaneously (Blair-Loy 2003; Crittenden 2001; Stone 2007). We find partial support for Hypothesis 1b. For mothers, there is no association between valuing leisure and importance of motherhood, but for non-mothers there is the expected significant negative association. This finding is consistent with Presser's (2005) argument that many women who delay childbearing for education and career development also gain an appreciation for leisure time and are reluctant to relinquish their free time for the added labor that children bring.

There is also partial support for Hypothesis 1c, because mothers employed full-time have significantly lower importance of motherhood values than mothers not in the paid labor force. If valuing employment and motherhood are at odds with each other, we would expect to see that even parttime employment should be associated with lower importance of mother- 
hood scores and that a similar pattern would hold for non-mothers. The pattern of results suggests that the association between full-time employment and importance of motherhood may reflect the challenges of work situations that are not family friendly rather than the contrary notion that work in the paid labor force itself reflects a woman's valuing of motherhood.

We had several reasons to expect an association between education and importance of motherhood, but, as Table 2 shows, there is no support for this relationship (Hypothesis 1d). In demographic research, education has a strong association with actual fertility (e.g., Yang and Morgan 2003), and popular press articles and books about careers and motherhood suggest that "careers" (rather than "jobs") compete with motherhood (e.g., Blair-Loy 2003, Hewlett 2002, Stone 2007). Yet, in our random sample of reproductive-age women, we find that education does not have a linear association with self reports of the importance of motherhood in women's lives. It is likely that the higher costs of motherhood for more highly educated women (e.g., Anderson, Binder, and Krause 2002; Budig 2006) and the greater benefits of motherhood for lower educated women (e.g., Edin and Kefalas 2005) shape women's fertility behavior more than their attitudes about the importance of motherhood in their lives. These findings are consistent with Duncan's (2005) argument that rationality is situation specific, meaning that individuals in different social locations can "rationally" value motherhood differently because they face different opportunities and constraints.

Turning to the hypothesized culture and identity associations, we find as expected that among both mothers and non-mothers, higher levels of religiosity are associated with higher importance of motherhood scores (Hypothesis $2 \mathrm{a}$ ), and more egalitarian gender attitudes are associated with lower importance of motherhood values (Hypothesis $2 b$ ). We did not specifically predict that egalitarian attitudes would have a significantly stronger association for non-mothers, but note that the effect is three times larger for non-mothers.

We proposed two conflicting hypotheses about the likely associations between race/ethnicity and importance of motherhood ( $2 \mathrm{c}$ and $2 \mathrm{~d}$ ). We find support for the first hypothesis; white mothers exhibit higher importance of motherhood scores than Black or Hispanic mothers. This may suggest that white women are more susceptible to the ideology of the cult of domesticity than are women from other groups. This is interesting in light of longstanding higher fertility rates among Black and Hispanic women (Yang and Morgan 2003). Our result may imply that higher fertility does not reflect higher importance of motherhood, but instead blocked opportunities for meaningful work or leisure opportunities (Edin and Kefalas 2005). 
We turn now to the life-course/situational hypotheses. Contrary to Hypothesis $3 \mathrm{a}$, age is not associated with importance of motherhood for mothers. While there is a significant negative association for non-mothers, the difference between mothers and non-mothers is not statistically significant. Why are importance of motherhood scores lower for older non-mothers? Women in their later thirties and forties who have no children have either lived their lives consistent with a lower priority on motherhood, or have lowered motherhood as a priority in response to not becoming mothers. The negative association for non-mothers also supports Gillespie's (2003) finding that women are more willing to express their desire to be childfree as they get older.

We anticipated that the ideological link between fertility and heterosexual marriage would translate into an association between importance of motherhood and marriage, but found only limited support for this hypothesis ( $3 \mathrm{~b})$. The behavioral connection between heterosexual marriage and childbearing has been declining (Bianchi and Casper 2002), but the normative expectation that motherhood is ideally coupled with marriage persists, even among those who do not follow this life-course pattern (Edin and Kefalas 2005). Among non-mothers, we find no differences in the importance of motherhood by marital status. We cannot rule out the possibility that smaller cell sizes contribute to this finding, but even when we collapse all non-married women together, we get the same finding.

Among mothers, widowed and never married women have significantly lower importance of motherhood scores than married women. The widowed mothers group is small $(\mathrm{n}=27)$, but the never married mother group is quite large $(n=394)$. It is likely that divorced and separated mothers do not differ significantly from married mothers because they have been married, but the effect for widows is puzzling. We suspect that the small number of young (under age 45) widowed mothers have the least idealized notions of motherhood because they did not anticipate becoming single mothers.

Considerable evidence that single motherhood is very challenging in the United States (e.g., Crittenden 2001; Moller 2002) helps explain why women in this situation are less likely to endorse idealized notions of motherhood. As is the case for race patterns, the ideology of intensive mothering and the cult of domesticity should have the least traction among the women who are in social-structural situations that make enacting idealized notions of motherhood the most difficult (Hays 1996). We therefore find only partial support for Hypothesis $3 \mathrm{~b}$. The difference in coefficients between never-married mothers and non-mothers is statistically significant. Never-married mothers are likely to have more realistic perspectives on 
motherhood than never-married non-mothers, contributing to the significantly lower coefficients among the mothers compared to non-mothers.

There is strong support for Hypothesis 3c; mothers have much higher importance of motherhood scores than non-mothers, controlling for all other variables. The constants in the multiple regression models represent the average importance of motherhood score when the variables in the model have a value of zero. The unadjusted difference in importance of motherhood scores $(0.75)$ is only slightly larger than the difference adjusted for all of the characteristics in the model (0.73). That mothers have much higher importance of motherhood scores than non-mothers is not surprising, but the consistency of this difference controlling for other characteristics that differ between mothers and non-mothers (e.g., age, education level, relationship status, employment status, etc.) is striking.

It is tempting to presume that women who place more importance on motherhood are simply more likely to become mothers. But it is likely more complicated than that. Many pregnancies are unintended (Abma et al. 1997), and even women who intend to become mothers may feel ambivalent about the day-to-day experience of mothering (Barrett and Wellings 2002; Miller 2007). Because most mothers spend considerable time engaged in caring for their children, expressing a belief that motherhood is not important would create cognitive dissonance (Festinger, Riecken, and Schachter 1956). Engaging in mothering practices is also likely to elevate the importance of motherhood in women's lives, regardless of their attitudes before becoming mothers. We are cautious about making causal assumptions about the effect of motherhood because the data are cross-sectional. Follow-up with longitudinal analyses of changes in the importance of motherhood over time, especially before and after becoming a mother, will help to sort out this issue.

It is interesting that non-mothers also have relatively high importance of motherhood scores (the mean is above the midpoint for the scale). This may indicate a social desirability effect - motherhood is an important cultural value. However, supplemental analyses reveal that only 12 percent of the non-mothers report that their ideal number of children is zero. The distribution of scores presented in Figure 1 suggests that, similar to mothers, most women's scores cluster in the higher ranges of the scale, despite some scores along the continuum.

\section{Discussion}

Can mothers simultaneously value work and motherhood? The answer from our analysis is yes. Contrary to many employers' expectations (Cor- 
rell, Bennard, and Paik 2007; Kennelly 1999), the importance of work and the importance of motherhood are positively correlated, and for non-mothers, there is no association. This finding debunks the myth that work-oriented women must be "anti-child" or that motherhood-oriented women must be "anti-work."

We can only speculate about the reasons why. Because motherhood has been so firmly linked with femininity, many high-achieving women may see successful mothering as a way to demonstrate that they are still appropriately feminine, despite their success in the (masculine) world of work (Gillespie 2003; Tichenor 2005). Both the lower importance of motherhood among full-time employed mothers (Crittenden 2001; Williams 2000) and non-mothers, who highly value leisure (Sayer, Bianchi, and Robinson 2004), are grounded in the empirical reality of the difficulty of combining work and/or leisure with intensive mothering.

We provide evidence that the importance of motherhood is about more than economic costs and benefits, or trade-offs between work and motherhood. Social situations explain more of the variance in the importance of motherhood than economic predictors. Our evidence that for mothers, valuing work and valuing motherhood are positively correlated, even controlling for many other characteristics, suggests that the construction of "mother" and "worker" as necessarily opposed identities is based on a false assumption about women's identities and attitudes. This is not to minimize the real difficulties that many women face navigating the gendered division of carework in many two-earner families, or as single mothers coping with gender- and race-biased state policies. For non-mothers, the idea of motherhood seems to be in competition more with leisure time than with employment, a finding that does not seem to be part of popular press notions of motherhood, but that has been proposed as an explanation for declining fertility rates (Presser 2005).

Future studies should explore the process through which women come to value motherhood, more or less, and whether their perceptions of the importance of motherhood have consequences for outcomes such as life satisfaction and well-being. For example, are women confronted with fertility barriers likely to lower their sense of the importance of motherhood and focus on other valuable interests, or to increase their sense of the importance of motherhood and pursue ways to overcome barriers to conception? Declining fertility rates and increased proportions of non-mothers highlight the need to understand the "decision" to become a mother. And yet, we are reluctant to even use the word "decision" because we are not convinced that the process is as active as that word implies. As is the case with many 
other important causal-order questions, we need more qualitative data to explore the meaning of motherhood in women's lives, and longitudinal data to assess the changes in importance of motherhood as women's life situations change.

Despite the questions that remain, the current study provides several important insights. First, there is no evidence that valuing motherhood is in conflict with valuing work success among non-mothers, and among mothers the association is positive, despite whatever employers may believe. Second, the importance of motherhood varies little by social class indicators, but does differ by race/ethnicity such that white mothers are more likely to endorse conventional, abstract notions of the importance on motherhood. Third, we show that the structural realities of motherhood in America have strong associations with the importance of motherhood. Similar to the efforts of Ireland (1993) and Gillespie (2003), we hope that these findings provide insights to help women "undo" gendered expectations that motherhood is essential to femininity (Deutsch 2007) in a way that helps women navigate pronatalist pressures around motherhood, and helps change schemas that conceptualize mothers and ideal-workers as incompatible statuses.

\section{References}

Abma, Joyce C., Anjali Chandra, William Mosher, Linda Peterson, and Linda Piccinino. 1997. Fertility, family planning, and women's health. Vital and Health Statistics 23 (19). Hyattsville, MD: National Center for Health Statistics.

Acker, Joan. 2006. Inequality Regimes: Gender, Class And Race In Organizations. Gender \& Society 20: 441-64.

Anderson, Deborah J., Melissa Binder, and Kate Krause. 2002. The motherhood wage penalty: Which mothers pay it and why? American Economic Review 92: 354-58.

Barrett, Geraldine, and Kaye Wellings. 2002. What is a 'planned' pregnancy? Social Science and Medicine 55: 545-57. Becker, Gary. 1991. A treatise on the family. Cambridge, MA: Harvard University Press.

Bianchi, Suzanne M., and Lynne M. Casper. 2002. Continuity and change in the American family. Thousand Oaks, CA: Sage Publications.

Blair-Loy, Mary. 2003. Competing devotions. Cambridge, MA: Harvard University Press.

Britton, Dana M. 2000. The epistemology of engendered organization. Gender \& Society 14: 418-35.

Budig, Michelle J. 2006. Gender, self-employment, and earnings: The interlocking structures of family and professional status. Gender \& Society 20: 725-53.

Bulcroft, Richard, and Jay Teachman. 2004. Ambiguous constructions: Development 
of a childless or childfree life course. In Handbook of contemporary families, edited by Marilyn Coleman and Lawrence H. Ganong. Newbury Park, CA: Sage Publications.

Collins, Patricia Hill 1990. Black feminist thought: Knowledge, consciousness and empowerment. Boston: Unwin Hyman.

Correll, Shelley J., Stephen Bennard, and In Paik. 2007. Getting a job: Is there a motherhood penalty? American Journal of Sociology 112: 1297-1338.

Crittenden, Ann. 2001. The price of motherhood: Why the most important job in the world is still the least valued. New York: Owl Books.

Deutsch, Francine. 2007. Undoing gender. Gender \& Society 21: 106-27.

Duncan, Simon. 2005. Mothering, class and rationality. The Sociological Review 53: 50-76.

Dunlap, Eloise, Gabriele Sturzenhofecker, and Bruce Johnson. 2006. The elusive romance of motherhood: Drugs, gender and reproduction in inner-city distressed households. Journal of Ethnicity and Substance Abuse 5: 1-27.

Edin, Kathryn, and Maria Kefalas. 2005. Promises I can keep: Why poor woman put motherhood ahead of marriage. Berkeley, CA: University of California Press.

Elder, Glen H., Jr., ed. 1985. Life course dynamics: Trajectories and transitions, 1968-1980. Ithaca, NY: Cornell University Press.

England, Paula. 2005. Gender inequality in labor markets: The role of motherhood and segregation. Social Politics 12: 264-88.

England, Paula, and Barbara S. Kilbourne. 1990. Feminist critiques of the separative model of self: Implications for rational choice theory. Rationality and Society 2: 156-71.

Festinger, Leon, Henry W. Riecken, and Stanley Schachter. 1956. When prophecy fails: A social and psychological study of a modern group that predicted the destruction of the world. University of Minnesota Press: St. Paul, MN.

Friedman, Debra, Michael Hechter, and Satoshi Kanazawa. 1994. A theory of the value of children. Demography 31: 375-400.

Gillespie, Rosemary. 2003. Childfree and feminine: Understanding the gender identity of voluntary childless women. Gender \& Society 17: 122-36.

Glauber, Rebecca. 2008. Race and gender in families and at work: The fatherhood wage premium. Gender \& Society 22: 8-30.

Hays, Sharon. 1996. The cultural contradictions of motherhood. New Haven, CT: Yale University Press.

Heaton, Tim. B., Cardell K. Jacobson, and Kimberlee Holland. 1999. Persistence and change in decisions to remain childless. Journal of Marriage and Family 61: 531-39.

Hechter, Michael, and Satoshi Kanazawa. 1997. Sociological rational choice theory. Annual Review of Sociology 23: 191-214.

Hewlett, Sylvia Ann. 2002. Creating a life: Professional women and the quest for children. New York: Miramax.

Houseknecht, Sharon K. 1987. Voluntary childlessness. In Handbook of marriage 
and the family, edited by Marvin P. Sussman and Suzanne K. Steinmetz. New York: Plenum Press.

Ireland, Mardy S. 1993. Reconceiving women: Separating motherhood from female identity. New York: Guildford.

Kendall, Carl, Aimee Afable-Munsuz, Ilene Speizer, Alexis Avery, Norine Schmidt, and John Santelli. 2005. Understanding pregnancy in a population of innercity women in New Orleans: Results of qualitative research. Social Science and Medicine 60: 297-311.

Kennelly, Ivy. 1999. "That single-mother element": How white employers typify Black women. Gender \& Society 13: 168-92.

Koropeckyj-Cox, T. and Pendell, G. 2007a. Attitudes about childlessness in the United States: Correlates of positive, neutral, and negative responses. Journal of Family Issues 28:1054-82.

Koropeckyj-Cox, Tanya, and Gretchen Pendell. 2007b. The gender gap in attitudes about childlessness in the United States. Journal of Marriage and Family 69: 899-913.

Landry, Bart. 2002. Black working wives. Berkeley: University of California Press. Lewin, Ellen. 1993. Lesbian mothers. Ithaca, NY: Cornell University Press.

Miller, Tina. 2007. "Is this what motherhood is all about?": Weaving experiences and discourse through transition to first-time motherhood. Gender \& Society 21(3): 337-58.

Misra, Joya, Stephanie Moller, and Michelle J. Budig. 2007. Work-family policies and poverty for partnered and single women in Europe and North America. Gender \& Society 21: 804-27.

Moller, Stephanie. 2002. Supporting poor single mothers: Gender and race in the U.S. welfare state. Gender \& Society 16: 465-84.

Morgan, Phillip, and Rosalind B. King. 2001. Why have children in the 21 st century? European Journal of Population 17: 3-20.

Myers, Scott M. 1997. Marital uncertainty and childbearing. Social Forces 75: 1271-89.

Nock, Steven. 1987. The symbolic meaning of childbearing. Journal of Family Issues 8: 373-94.

Presser, Harriet B. 2005. The importance of gender relations for understanding low fertility and single motherhood. In The new population problem, edited by Alan Booth and Ann C. Crouter. Lawrence Erlbaum Associates: Mahwah, NJ.

Ridgeway, Celia L., and Shelley J. Correll. 2004. Motherhood as a status characteristic. Journal of Social Issues 60: 683-700.

Risman, Barbara J., and Myra Marx Ferree. 1995. Making gender visible. American Sociological Review 60: 775-82.

Sayer, L. C., S. M. Bianchi, and J. P. Robinson. 2004. Are parents investing less in children? Trends in mothers' and fathers' time with children. American Journal of Sociology 110: 1-43.

Schoen, Robert, Young J. Kim, Constance A. Nathanson, Jason M. Fields, and Nan Marie Astone. 1997. Why do Americans want more children? Population and Development Review 23: 333-58. 
Segura, Denise. 1994. Working at motherhood: Chicana and Mexican immigrant mothers and employment. In Mothering: Ideology, experience, and agency, edited by Evelyn Nakano Glenn, Grace Chang, and Linda Rennie Forcey. New York: Routledge.

Stone, Pamela. 2007. Opting out: Why women really quit careers and head home. Berkeley, CA: University of California Press.

Tichenor, Veronica. 2005. Earning more and getting less: Why successful women can't buy equality. NJ: Rutgers University Press.

Ulrich, Miriam, and Ann Weatherall. 2000. Motherhood and infertility: Viewing motherhood through the lens of infertility. Feminism \& Psychology 10: 323-36.

Wall, Glenda, and Stephanie Arnold. 2007. How involved is involved fathering? An exploration of the contemporary culture of fatherhood. Gender \& Society 21: 508-27.

Williams, Joan. 2000. Unbending gender: Why family and work conflict and what to do about it. New York: Oxford University Press.

Wood, Glendice, and Janice Newton. 2006. Childlessness and women managers: 'Choice,' context, and discourses. Gender Work and Organization 13: 338-58.

Yang, Yang and S. Philip Morgan. 2003. How big are educational and racial fertility differentials in the U.S.? Social Biology 51: 167-87.

Julia McQuillan is an associate professor of sociology at the University of Nebraska. She studies the social and behavioral consequences of infertility, illness trajectories, race and gender contexts of worker outcomes, and gender dimensions of children's literature, sports, delinquency, and academia. She is a co-investigator on the National Study of Fertility Barriers.

Arthur L. Greil is professor of sociology at Alfred University. He has written extensively on psychosocial aspects of infertility and is on the research team responsible for conducting the National Study of Fertility Barriers. He also does research in the sociology of religion, focusing on conversion, quasi-religion, and defining religion.

Karina M. Shreffler is an assistant professor of Human Development and Family Science at Oklahoma State University. Her research focuses on childbearing intentions and behaviors of employed women, fertility postponement, infertility, and reproductive health disparities.

Veronica Tichenor is an assistant professor of sociology at SUNY-Institute of Technology. Her research interests center around the links between feminine identities, power, and violence: the effects of women's income on their relative power in marriage, intergenerational transmission of attitudes towards violence (mother to daughter), and feminine identity construction in a context of violence. 